\title{
Structural Parameter Analysis of Mg Doped ZnO Nano Rods by Fuzzy Logic Controller
}

\author{
https://doi.org/10.3991/ijes.v9i2.21911 \\ Saher Manzoor ${ }^{(凶)}$, Maham Akhlaq, Nimra Tariq Butt \\ Government College University Lahore, Lahore, Pakistan \\ sahermanzoorlegmail.com \\ Muhammad Faisal Wasim \\ Government Dyal Singh College, Lahore, Pakistan
}

\begin{abstract}
Zinc Oxide ( $\mathrm{ZnO})$ nanorods have been extensively studied owing to their exceptional materials properties as well as outstanding performance in optics, electronics, and photonics. Lately, photocatalytic applications of $\mathrm{ZnO}$ nanorods are of greater interest in ecological defense applications. When magnesium is doped with $\mathrm{ZnO}$, the properties of nanorods can be improved for several potential applications in diverse fields of science and technology. In this work, we have studied the effect of parameters like doping concentration and temperature for solution-based growth on the diameter and length of the nanorods grown on the glass substrate. Fuzzy Logic Controller (FLC) has been used to calculate precise and accurate results as the FLC is based on human-like reasoning. The analysis of the dependence of diameter and length of Magnesium $(\mathrm{Mg})$ doped $\mathrm{ZnO}$ nanorods on different input parameters is done by fuzzy simulations and the simulated results are then compared with the calculations done using Mamdani's model. An almost negligible percentage error is calculated between the simulated and calculated values. As at nanoscale the size of the structure is crucial, the results of this study demonstrate that the synthesis parameters can be easily optimized to get $\mathrm{Mg}$ doped $\mathrm{ZnO}$ nanorods of the desired size to be used in specified application purpose.
\end{abstract}

Keywords - Nanorods, Magnesium Doped Zinc Oxide, Fuzzy Analysis

\section{Introduction}

Now-a-days nanomaterials have gained considerable attention due to their tremendous revolution in different fields including medicine, food, and others, etc. The structures of nanomaterials are different from macroscale structures as they are diverse and complex. Nanomaterials have become broadly studied for the past few years due to their unique properties which are, surface and edge effect, minor size effect, improved surface-to-volume ratio, as well as quantum size effect. Through the fast development in nanotechnology, a large number of engineered nanomaterials have been smeared in agriculture, industry, service, food, and medicine [1]. Among numerous nanomaterials that are semiconductors in nature, $\mathrm{ZnO}$ has gathered great attention due to 
its remarkable properties and wide range of applications. $\mathrm{ZnO}$ is normally obtainable in white powder form and insoluble in water. The high electron mobility and wider band-gap of $\mathrm{ZnO}$ make it appropriate for high temperature and high voltage applications [2-4].

$\mathrm{ZnO}$ can display a wide range of nanostructures, exceptional semiconducting, piezoelectric, and optical properties therefore have been considered for a wides range of applications. Other most significant features of $\mathrm{ZnO}$ nanomaterials are their easy biodegradability and low toxicity. $\mathrm{ZnO}$ is a semiconductor with a direct bandgap that is $3.37 \mathrm{eVand}$ has an exciton binding energy of $60 \mathrm{meV}$. $\mathrm{ZnO}$ exhibits immediate Ultraviolet (UV) emission, piezoelectricity, and transparent conductivity. Additionally, $\mathrm{ZnO}$ is bio-harmless and bio-friendly and therefore used for biomedical applications deprived of the coating. Concentrated research has been fixated on the fabrication of One Dimensional (1D) $\mathrm{ZnO}$ nanostructures and in a correlation of morphologies with size-associated photosensitive and electrical properties. Numerous types of $\mathrm{ZnO}$ nanostructures have been recognized, such as nanorods, nanodots, nanowires, nanotubes, nanobelts, nanobridges and nanowalls, nanonails, seamless nanorings, nanohelixes, mesoporous single crystal nanowires, as well as polyhedral enclosures [5-8]. $\mathrm{ZnO}$ nanorods have been extensively studied owing to their exceptional materials properties as well as outstanding performance in optics, electronics, and photonics. Lately, photocatalytic applications of $\mathrm{ZnO}$ nanorods are of greater interest in ecological defense applications. Due to n-type structures, it has been observed that nanorods have excellent piezoelectric and pyroelectric properties [9-11].

$\mathrm{ZnO}$ thin films have a wide range of applications in many optoelectronic devices including sensors, Photodetectors, spintronic devices, light-emitting diodes, and energy harvesting. It has been reported the addition of doping elements results in the modification of properties of $\mathrm{ZnO}$. $\mathrm{Mg}$ doped $\mathrm{ZnO}$ thin films have large exciton binding energy, can be grown at low temperature, and also the bandgap can be tuned by changing the incorporation amount of $\mathrm{Mg}$ [12]. Shewale et. al. [13] reported that variation in processing time results in a change of film thickness, growth time have a direct relation with the film thickness of $\mathrm{Mg} \mathrm{ZnO}$ nanorods. It has been reported that the addition of $\mathrm{Mg}$ in $\mathrm{ZnO}$ nanorods can result in enhanced optoelectrical properties and increased electrical conductivity [14]. Yang et. al. [15] proved that the diameter of $\mathrm{ZnO}$ nanorods can be controlled successfully by adjusting the $\mathrm{pH}$ of the medium. $\mathrm{Al}$ Hardan et. al. [16] synthesized $\mathrm{ZnO}$ nanorods with different concentrations of $\mathrm{Mg}$ doping and it is noticed that by the addition of $\mathrm{Mg}$ the nanorods became hallow. Guo et. al. [17] studied the effect of doping content of $\mathrm{Mg}$ and different substrates for the growth of nanorods, and it is observed that $\mathrm{Mg}$ doping enhances crystalline quality and morphology. Also, $\mathrm{ZnO}$ substrate is a good choice for $\mathrm{Mg} \mathrm{ZnO}$ nanorods growth. Azzez et. al. [18] studied the effect of temperature on the $\mathrm{Mg}$-doped $\mathrm{ZnO}$ nanorods synthesized via the hydrothermal method. It is proved from the results that at a moderate temperature of $150^{\circ} \mathrm{C}$ improved crystal quality and uniform size distributed nanorods can be obtained. Winkler et. al. [19] fabricated $\mathrm{Mg}$ dope $\mathrm{ZnO}$ film via the chemical bath method and results reveal that the film can only be grown in a narrow $\mathrm{pH}$ window. Kasi et. al [20] studied the annealing temperature effect on the antibacterial action and morphology of $\mathrm{Mg}$-doped $\mathrm{ZnO}$ nanorods. Mohar et al. [21] studied the 
dependency of Mg-doped $\mathrm{ZnO}$ nanorods optical properties on $\mathrm{Al}$ dopant. Qi et al. [22] proposed a method that was observed promising as a facetious and innovative way for changing light-trapping aptitudes of $\mathrm{Mg}$-doped $\mathrm{ZnO}$ nanorods thin films appropriate for polymer based solar cells as well as other $\mathrm{ZnO}$ based photonic and optoelectronic devices. Senol et al. [23] proposed how the bandgap of $\mathrm{Mg}$-doped $\mathrm{ZnO}$ nanorods engineering has been prepared by hydrothermal method and has applications in different industries.

Numerous methods that have been adapted for the growth of nano-rods include hydrothermal processes, pulsed laser deposition, vapor-liquid-solid deposition, seedlayer deposition, and Chemical bath deposition [24, 25]. For solution-based techniques, significant properties of the solution include the concentration of metal salts, additives, solution composition, saturation level, and $\mathrm{pH}[26,27]$. The parameters important for the growth process that play role in tuning the properties include deposition time, temperature, and stirring rate [28, 29].

Several simulation tools that can be adopted to check and estimate the process parameters include COMSOL [30], ANSYS [31], TRNASYS [32], and MATLAB [33]. The FLC is a method to incorporate human-like reasoning in a control system. FLS works for any type of input irrespective of noisy or distorted information. Since the execution is based on "degrees of truth" it gives a very logical solution to even complex problems. FLC provides rules for mathematical models to resolve their complexity [34-36].

In this paper, the growth of $\mathrm{Mg}$ doped $\mathrm{ZnO}$ nanorods on glass substrate has been observed. Then to calculate the precise diameter and length of $\mathrm{Mg}$-doped $\mathrm{ZnO}$ nanorods, the input parameters of temperature and doping concentration have been applied to FLC and simulation is done on MATLAB. The accuracy of the obtained results is crucial for applications in various fields by synthesis via chemical methods.

\section{Synthesis Method}

A glass substrate is cleaned with DI water and acetone. After cleaning the glass substrate is dried for the growth of $\mathrm{Mg}$ doped $\mathrm{ZnO}$ nanorods. A $20 \mathrm{mM}$ solution of Hexamine and zinc acetate with $\mathrm{Mg}$ as doper in DI water is prepared. This solution is then added to the self-designed setup for chemical bath deposition of the rods. The temperature of the water bath is set between $75-95^{\circ} \mathrm{C}$. then the substrate is immersed vertically into the solution for about 5 hours. The substrate is then washed with DI water and baked for about 2 hours at $450^{\circ} \mathrm{C}$. The schematic for the synthesis procedure is shown in Fig. 1. 


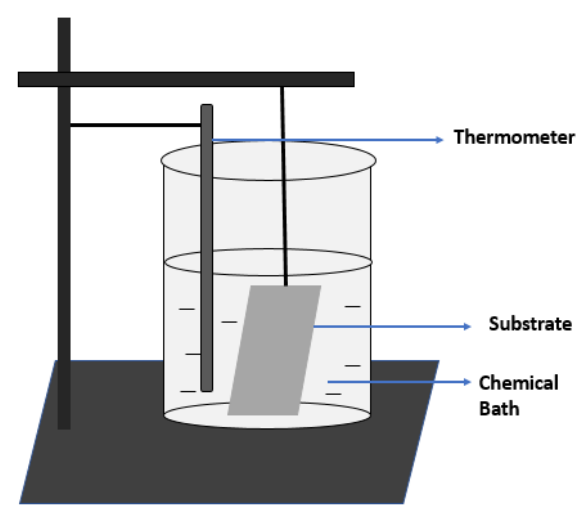

Fig. 1. Schematic of synthesis process

\section{$3 \quad$ Methodology}

Fuzzy simulation and analysis has been carried out with MATLAB using Mamdani's model. The FLC block in Simulink has process temperature and Mg doping concentration as two inputs and two outputs including Rod length and Rod diameter. The two input parameters are assigned with three membership functions making 9 rules for the fuzzy analysis. The range of values is selected for each membership function. The range of the process temperature is selected from a minimum of $75-95^{\circ} \mathrm{C}$, whereas the range for the $\mathrm{Mg}$ doping concentration in the $\mathrm{ZnO}$ nano-crystal is set from the minimum value of $0-10 \%$. The output parameters of length of rod are taken in the range of 1-20 $\mu \mathrm{m}$ and the diameter of the rod is taken in the range of 50-500nm. Fig. 2 represents the FLC block for two inputs and two corresponding outputs.

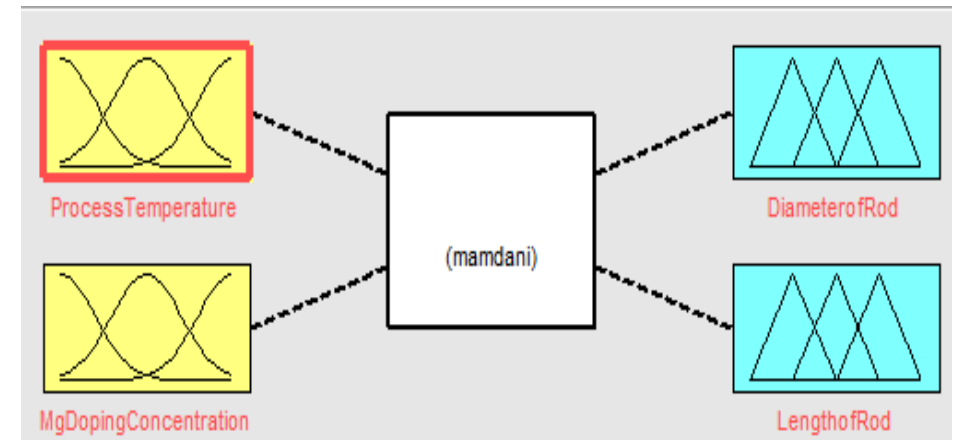

Fig. 2. FLC Interface for 2 Inputs and 2 Outputs

Fig. 3(a-d) show the membership functions and ranges of the inputs and output. 

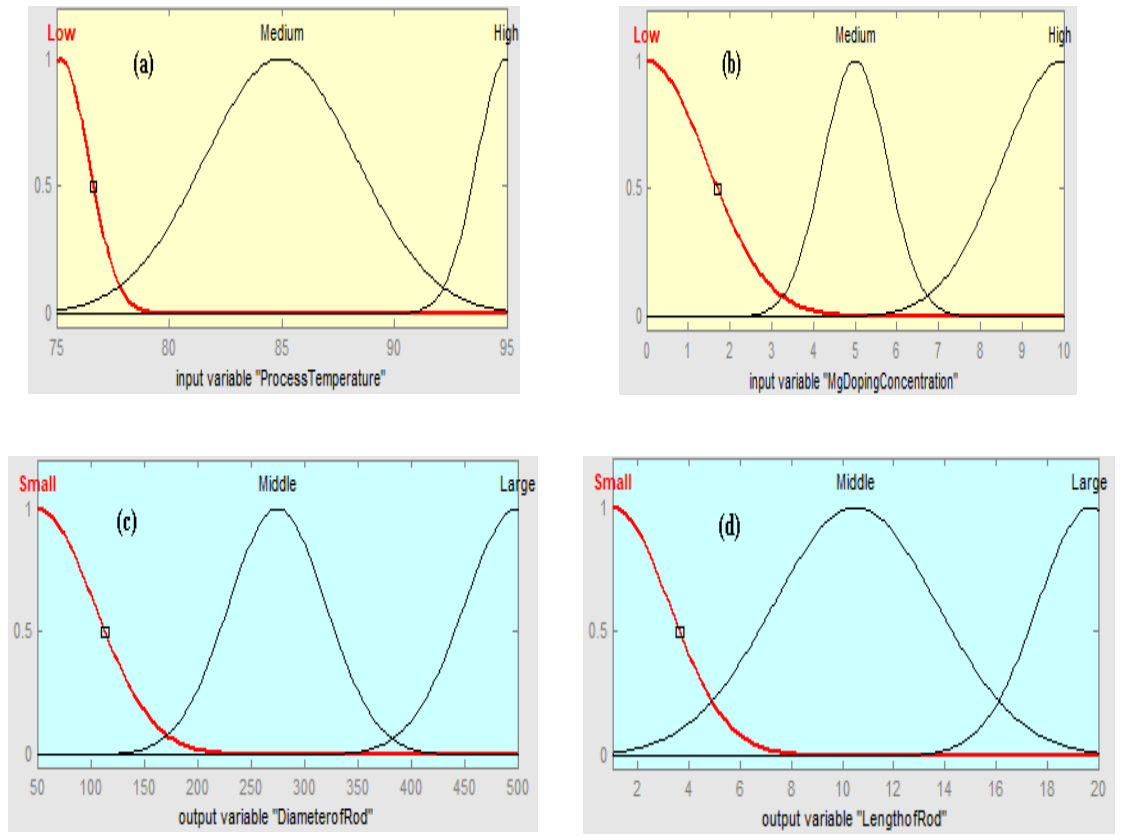

Fig. 3. Membership Function of Input and Output along with its Ranges (a) Process Temperature (b) Mg Doping Concentration (c) Diameter of Rod (d) Length of Rod

Membership functions for input 1 process temperature are taken as low, medium, and high. Membership functions for input $2 \mathrm{Mg}$ doping concentration are taken as low, medium, and high. Membership functions for the output diameter of the rod are taken as small, middle, and large. Membership functions for the output length of the rod are taken as small, medium, and large as shown in Table 1.

Table 1. Ranges of Every Membership Function of Input and Output

\begin{tabular}{|c|c|c|}
\hline Input/Output & Membership Function & Ranges \\
\hline \multirow{3}{*}{ Process Temperature $\left({ }^{\circ} \mathrm{C}\right)$} & Low & $75-80$ \\
\hline & Medium & $77-93$ \\
\hline & High & $90-95$ \\
\hline \multirow{3}{*}{ Mg Doping Concentration (\%) } & Low & $0-4.5$ \\
\hline & Medium & $2.5-7.5$ \\
\hline & High & $5.5-10$ \\
\hline \multirow{3}{*}{ Diameter of the Rods (nm) } & Small & $50-250$ \\
\hline & Middle & $150-450$ \\
\hline & Large & $350-500$ \\
\hline \multirow{3}{*}{ Length of the Rods $(\mu \mathrm{m})$} & Small & $1-8$ \\
\hline & Middle & $1.5-19.5$ \\
\hline & Large & $14-20$ \\
\hline
\end{tabular}


Because there are 2 input variables, a total of 9 rules have been designed for simulations. For a set of two rules from both inputs, there are two corresponding outputs. The rules are set based on knowledgeable data and literature.

Based on these rules, 3D graphs are studied for input and their effect on output. Fig. 4 shows 3D graphs between input and output. Fig. 4(a) shows the graph between process temperature and $\mathrm{Mg}$ doping concentration and its effect on the diameter of the prepared rods. Fig. 4(b) shows the graph between process temperature and Mg doping concentration and its effect on the length of the prepared rods.
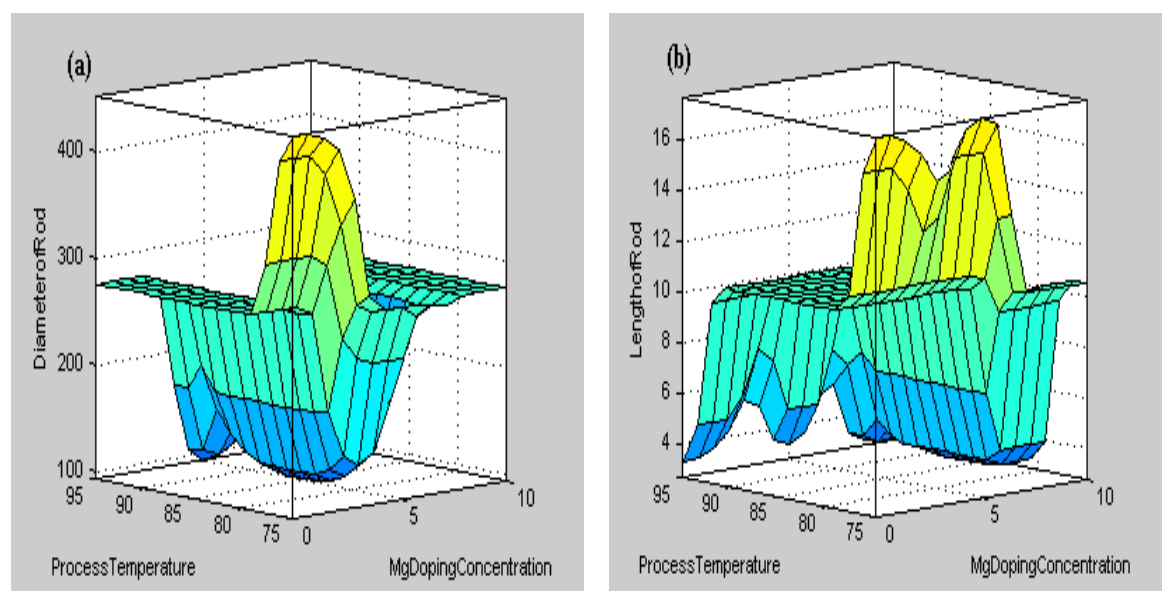

Fig. 4. 3D Graphs between (a) Process Temperature and Mg Doping Concentration with the Diameter of Rod as Output (b) Process Temperature and Mg Doping Concentration with Length of Rod as Output

The diameter of the rod decreases with the increase in Mg doping owning to the addition of conductive materials which results in the decrease in crystallite size of the prepared nanostructure. Because of the small ionic radii of $\mathrm{Mg}$, its incorporation in the $\mathrm{ZnO}$ nano-crystal results in a decrease in its crystallite size. Similarly, with high process temperature of chemical bath deposition highly hexagonal structured with small diameter and length of nano-rods is prepared. Higher temperature will result in smoother and better growth of $\mathrm{Mg}$ doped nano-rod material.

Fig. 5 represents the defined rules viewed by Matlab Rule viewer, which shows that for process temperature $90.1 \mathrm{oC}$ and $\mathrm{Mg}$ doping concentration of $7.17 \%$ the output diameter of the rod is $266 \mathrm{~nm}$ and rod length $5.98 \mu \mathrm{m}$. 


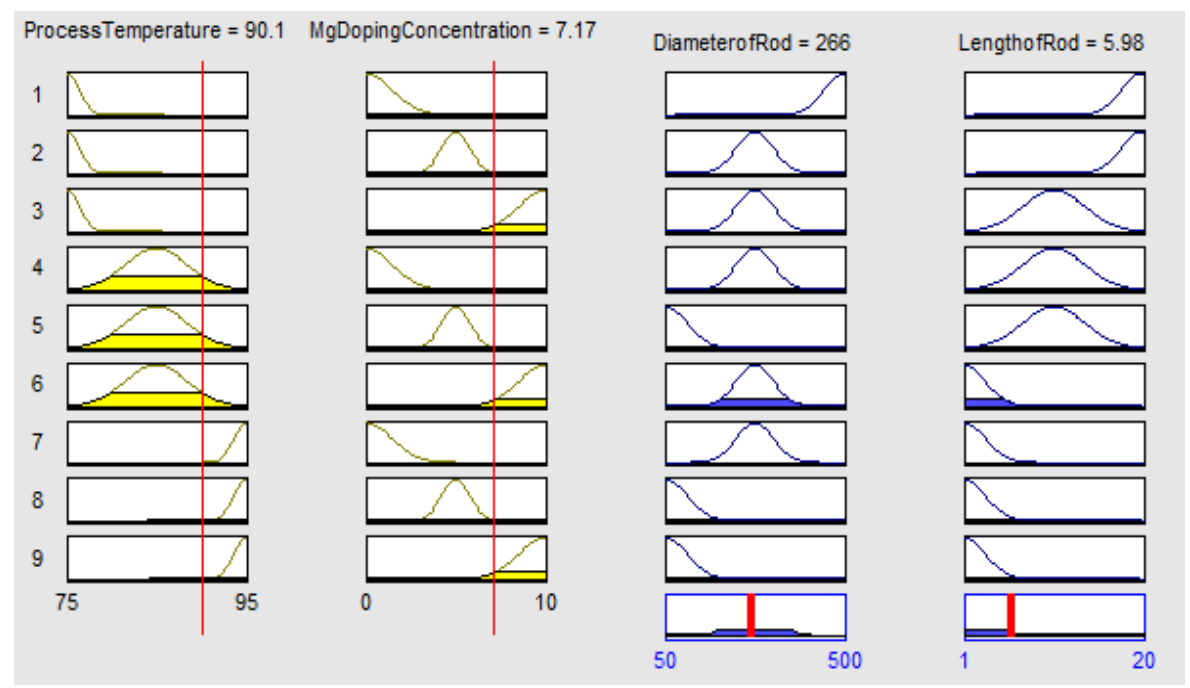

Fig. 5. Rule Viewer for Crisp Value Selection

\section{Results and Discussion}

Crisps values of the inputs and the corresponding output crisp value are noted for the calculations of the results and rule viewer as shown in Fig. 4. The selected input crisp values for process temperature $90.1^{\circ} \mathrm{C}$ and $\mathrm{Mg}$ doping concentration of $7.17 \%$ the output diameter of the rod is $266 \mathrm{~nm}$ and rod length $5.98 \mu \mathrm{m}$ as shown in Fig. 4.

These values of membership functions are calculated as:

$$
\begin{gathered}
\mathrm{e}_{1}=(95-90.1) / 95=0.05^{\circ} \mathrm{C} \\
\mathrm{e}_{2}=1-\mathrm{e}_{1}=1-0.05=0.95^{\circ} \mathrm{C}
\end{gathered}
$$

For the crisp value of the $\mathrm{Mg}$ doping concentration, the values of membership function are calculated as:

$$
\begin{gathered}
\mathrm{e}_{3}=(10-7.17) / 10=0.283 \% \\
\mathrm{e}_{4}=1-\mathrm{e}_{3}=1-0.0106=0.717 \%
\end{gathered}
$$

For the corresponding membership function values $\mathrm{e}_{1}, \mathrm{e}_{2}, \mathrm{e}_{3}$, and $\mathrm{e}_{4}$, the following four rules out of a total of nine rules are selected. Table 2 shows the calculations performed for minimum value (Mi) of membership functions, singleton values ( $\mathrm{Si}$ ) of the film diameter of the rod, and its estimated value. 
Table 2. Calculations Using MAMDANI's Model for Rod Diameter Calculation

\begin{tabular}{|l|l|c|c|c|c|c|}
\hline Process Temperature & Mg Doping Concentration & \multicolumn{2}{|c|}{ Membership Functions } & Mi & Si & Mi $\mathbf{x}$ Si \\
\hline Small & Medium & $\mathrm{e}_{1} \wedge \mathrm{e}_{3}$ & $0.05^{\wedge} 0.283$ & 0.05 & 3.5 & 0.175 \\
\hline Small & Small & $\mathrm{e}_{1} \wedge \mathrm{e}^{4}$ & $0.05^{\wedge} 0.717$ & 0.05 & 3.5 & 0.175 \\
\hline Large & Medium & $\mathrm{e}_{2} \mathrm{e}_{3}$ & $0.95^{\wedge} 0.283$ & 0.283 & 0.5 & 0.9905 \\
\hline Medium & Medium & $\mathrm{e}_{2}{ }^{\wedge} \mathrm{e}_{4}$ & $0.95^{\wedge} 0.717$ & 0.717 & 3.5 & 2.51 \\
\hline
\end{tabular}

Where $^{\wedge}$ is used for comparison between respective Membership functions values

$\Sigma(\mathrm{Mi} \times \mathrm{Si})=3.001$

$\Sigma \mathrm{Mi}=1.1$

$$
\text { Mamdani's Model }=\left[\frac{\sum(\mathrm{Mi} \times \mathrm{Si})}{\sum \mathrm{Mi}}\right] \times 100
$$

Mamdani Model Value for Diameter $=(3.001 / 1.1) \times 100=272 \mathrm{~nm}$

The resultant of the calculations by Mamdani's model is $272 \mathrm{~nm}$ which is approximately equal to the crisp value of the length of rods by rule viewer for the corresponding input crisp values. The difference and percentage error difference between the simulated value and the theoretically calculated value is as follows:

$$
\text { Percemtage Errpr }=\frac{\text { Difference }}{100}=0.06 \%
$$

Table 3 shows the calculated value of length using the input crisp values.

Table 3. Calculations Using MAMDANI's Model for Rod Diameter Calculation

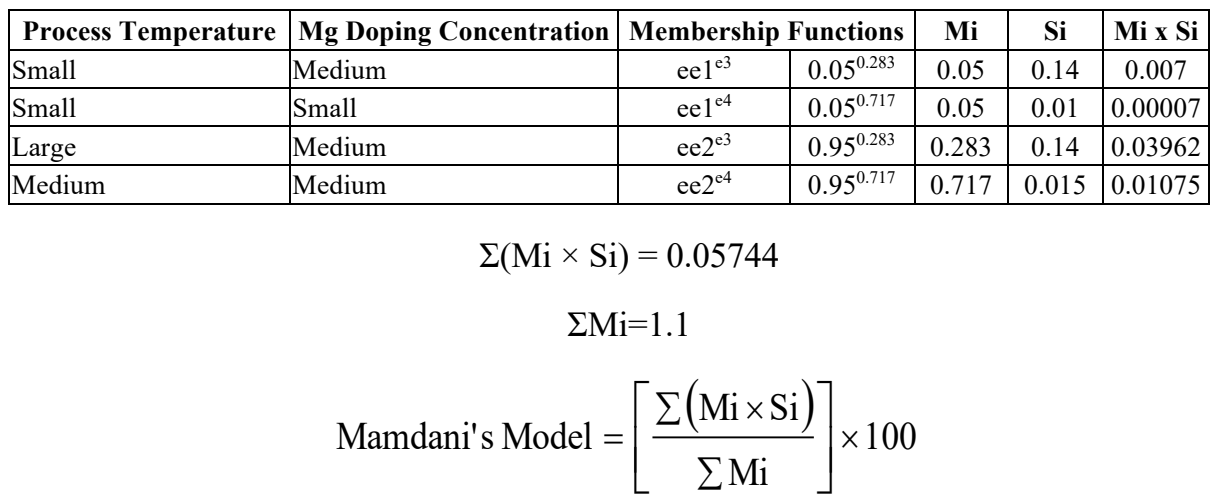

Mamdani Model Value for Diameter $=(0.05744 / 1.1) \times 100=5.22 \mu \mathrm{m}$

The resultant of the calculations by Mamdani's model is $5.22 \mu \mathrm{m}$ which is approximately equal to the crisp value of the diameter of rods by rule viewer for the corre- 
sponding input crisp values. The difference and percentage error difference between the simulated value and the theoretically calculated value is as follows"

$$
\text { Perctange Error }=\frac{\text { Difference }}{100}=0.0076 \%
$$

These results calculated using the logic control system with human-like reasoning can be utilized for the synthesis of the film with desired length and diameter of rods by controlling the parameters. If the parameters can be controlled successfully then by using chemical methods the rod length and diameter can be optimized with better performance for the application for which it is to be used.

A comparative analysis between the previously carried out research work and the finding of this work shows that the diameter, as well as the length of the rods decreases with $\mathrm{Mg}$ doping concentration in $\mathrm{ZnO}$ nanorods. Various previously carried out work co-relate with this finding. Sahoo et al reported the preparation of a $5 \% \mathrm{Mg}$ doped $\mathrm{ZnO}$ sample having a diameter of $113 \mathrm{~nm}$ gradually decreases as compared to that of pristine $\mathrm{ZnO} 182 \mathrm{~nm}$ [37].

\section{Conclusion}

In this paper, we have performed the analysis of structural parameters of $\mathrm{Mg}$ doped $\mathrm{ZnOnanorods}$ using the FLC. The parametric analysis is performed taking temperature and doping concentration during the synthesis process as input. The effect of variation of these inputs during the chemical bath synthesis on the length and diameter of nanorods is studied. The difference between the calculated and simulated is almost negligible, hence the geometric features of the rods which are the length and diameter of the rod can be optimized effectively by simply varying the process parameters during the synthesis. These simulations help us to synthesize rods of desired features to be used successively in practical applications. As at nanoscale the size and geometry of the synthesized structure are crucial and if we can optimize the parameters of synthesis then we can get desired size structure easily for any application.

\section{Acknowledgement}

The authors are thankful to Nano-electronics Research Lab, GC University Lahore for providing facilities to carry out this research work.

\section{$7 \quad$ References}

[1] C. Buzea, I. I. Pacheco, and K. Robbie, (2007), "Nanomaterials and nanoparti-cles: sources and toxicity, " Biointerphases, Vol. 2, pp. MR17-MR71. https://doi.org/10. $1116 / 1.2815690$

[2] A. Janotti and C. G. Van de Walle, (2009), "Fundamentals of zinc oxide as a semiconductor, " Reports on progress in physics, Vol. 72, pp. 126501. https://doi.org/10.1088/0034$\underline{4885 / 72 / 12 / 126501}$ 
[3] M. Awalludin, M. H. Mamat, M. Z. Sahdan, Z. Mohamad, and M. Rusop, (2013), "Zinc oxide nanorods characteristics prepared by sol-gel immersion meth-od immersed at different times," in Advanced Materials Research, pp. 375-379. https://doi.org/10.4028/ www.scientific.net/amr.667.375

[4] S. Ji and C. Ye, (2008), "Synthesis, growth mechanism, and applications of zinc oxide nanomaterials," Journal of materials science \& technology, Vol. 24, pp. 457.

[5] S. Baruah, M. Jaisai, R. Imani, M. M. Nazhad, and J. Dutta, (2010), "Photo-catalytic paper using zinc oxide nanorods," Science and Technology of Advanced Materials. https://doi. org/10.1088/1468-6996/11/5/055002

[6] Y. Yang and T. Liu, (2011), "Fabrication and characterization of graphene oxide/zinc oxide nanorods hybrid, " Applied Surface Science, Vol. 257, pp. 8950-8954. https://doi.org/ 10.1016/j.apsusc.2011.05.070

[7] A. Manekkathodi, M. Y. Lu, C. W. Wang, and L. J. Chen, (2010),"Direct growth of aligned zinc oxide nanorods on paper substrates for low-cost flexible electronics," Advanced materials, Vol. 22, pp. 4059-4063. https://doi.org/10.1002/adma.201001289

[8] X. Dong, Y. Cao, J. Wang, M. B. Chan-Park, L. Wang, W. Huang, (2012), "Hybrid structure of zinc oxide nanorods and three dimensional graphene foam for supercapacitor and electrochemical sensor applications," RSC advances, Vol. 2, pp. 4364-4369. https://doi.org/10.1039/c2ra01295b

[9] R. Pietruszka, B. S. Witkowski, S. Gieraltowska, P. Caban, L. Wachnicki, E. Zielony, (2015), "New efficient solar cell structures based on zinc oxide nanorods," Solar Energy Materials and Solar Cells, Vol. 143, pp. 99-104. https://doi.org/10.1016/j.solmat.2015. $\underline{06.042}$

[10] M. Marie, S. Mandal, and O. Manasreh, (2015), "An electrochemical glucose sensor based on zinc oxide nanorods," Sensors, Vol. 15, pp. 18714-18723. https://doi.org/10.3390/ $\underline{\mathrm{s} 150818714}$

[11] T. Bora, D. Zoepfl, and J. Dutta, (2016), "Importance of plasmonic heating on visible light driven photocatalysis of gold nanoparticle decorated zinc oxide na-norods," Scientific reports, Vol. 6, pp. 1-10. https://doi.org/10.1038/srep26913

[12] P. Shewale and Y. Yu, (2016), "Structural, surface morphological and UV photodetection properties of pulsed laser deposited Mg-doped $\mathrm{ZnO}$ nanorods: ef-fect of growth time," Journal of Alloys and Compounds, Vol. 654, pp. 79-86. https://doi.org/10.1016 i.jallcom.2015.09.048

[13] P. Shewale, N. Lee, S. Lee, and Y. Yu, (2015), "Physical and UV photodetec-tion properties of pulsed laser deposited Mg0. 05Zn0. $95 \mathrm{O}$ thin films: Effect of ox-ygen pressure," Journal of Alloys and Compounds, Vol. 640, pp. 525-533. https://doi.org/10.1016 /j.jallcom.2015.03.232

[14] R. Mohamed, J. Rouhi, M. F. Malek, A. S. Ismail, S. Alrokayan, H. A. Khan, (2016), "Sol gel synthesized zinc oxide nanorods on single and Co-doped $\mathrm{ZnO}$ seed layer templates: Morphological, optical and electrical properties," Int. J. Electro-chem. Sci, Vol. 11, pp. 2197-2204.

[15] W. Zeng, X. Yang, M. Shang, X. Xu, W. Yang, and H. Hou, (2016), "Fabrica-tion of Mgdoped $\mathrm{ZnO}$ nanofibers with high purities and tailored band gaps," Ce-ramics International, Vol. 42, pp. 10021-10029. https://doi.org/10.1016/j.ceramint.2016.03.105

[16] N. H. Al-Hardan, M. A. A. Hamid, A. Jalar, R. Shamsudin, and N. K. Oth-man, (2017), "Synthesis of Magnesium-Doped ZnO Rods via Hydrothermal Method: A Study of the Structural and Optical Properties," ECS Journal of Solid State Science and Technology, Vol. 6, p. P571. https://doi.org/10.1149/2.0021709jss 
[17] N. Guo, Y. Wang, X. Wei, Y. Yu, M. Ding, and X. Xu, (2016), "Effects of Mg-contents and substrate parameters on structure and optical properties of $\mathrm{Mg}$-doped $\mathrm{ZnO}$ nanorods fabricated by hydrothermal method," Journal of Materials Science: Materials in Electronics, Vol. 27, pp. 6665-6672. https://doi.org/10.1007/s10854-016-4613-3

[18] S. A. Azzez, Z. Hassan, J. Hassan, M. Mukhlif, M. S. Mahdi, and M. Bououdina, (2017), "Effect of temperature on hydrothermally grown high-quality single-crystals Mg-doped $\mathrm{ZnO}$ nanorods for light-emitting diode application," Jour-nal of Luminescence, Vol. 192, pp. 634-643. https://doi.org/10.1016/j.jlumin.2017.07.050

[19] N. Winkler, S. Edinger, W. Kautek, and T. Dimopoulos, (2018), "Mg-doped ZnO films prepared by chemical bath deposition," Journal of materials science, Vol. 53, pp. 51595171. https://doi.org/10.1007/s10853-017-1959-8

[20] G. Kasi, K. Viswanathan, and J. Seo, (2019), "Effect of annealing tempera-ture on the morphology and antibacterial activity of Mg-doped zinc oxide nano-rods," Ceramics International, Vol. 45, pp. 3230-3238. https://doi.org/10.1016/j.ceramint.2018.10.226

[21] R. S. Mohar, I. Sugihartono, V. Fauzia, and A. A. Umar, (2020), "Depend-ence of optical properties of $\mathrm{Mg}$-doped $\mathrm{ZnO}$ nanorods on $\mathrm{Al}$ dopant," Surfaces and Interfaces, Vol. 19, p. 100518. https://doi.org/10.1016/j.surfin.2020.100518

[22] S. Qi, X. Yu, X. Yu, J. Zhang, L. Chen, Y. Zhou, (2019), "Effects of non-stoichiometric ratio on optical characteristics of Mg-doped $\mathrm{ZnO}$ nanorods," Optical Materials, Vol. 90, pp. 180-186. https://doi.org/10.1016/j.optmat.2019.02.048

[23] S. D. Senol, C. Boyraz, E. Ozugurlu, A. Gungor, and L. Arda, (2019), "Band gap engineering of $\mathrm{Mg}$ doped $\mathrm{ZnO}$ nanorods prepared by a hydrothermal method," Crystal Research and Technology, Vol. 54, p. 1800233. https://doi.org/10.1002/crat.201800233

[24] M. Shkir, M. Arif, V. Ganesh, M. Manthrammel, A. Singh, I. Yahia, (2018), "Investigation on structural, linear, nonlinear and optical limiting properties of sol-gel derived nanocrystalline $\mathrm{Mg}$ doped $\mathrm{ZnO}$ thin films for optoelectronic applica-tions," Journal of Molecular Structure, Vol. 1173, pp. 375-384. https://doi.org/10.1016/j.molstruc.2018.06.105

[25] N. Kumar and A. Srivastava, (2018), "Green photoluminescence and photo-conductivity from screen-printed $\mathrm{Mg}$ doped $\mathrm{ZnO}$ films," Journal of Alloys and Compounds, Vol. 735, pp. 312-318. https://doi.org/10.1016/j.jallcom.2017.11.024

[26] V. Khorramshahi, J. Karamdel, and R. Yousefi, (2018), "Acetic acid sensing of Mg-doped $\mathrm{ZnO}$ thin films fabricated by the sol-gel method," Journal of Materi-als Science: Materials in Electronics, Vol. 29, pp. 14679-14688. https://doi.org/10.1007/s10854-018-9604-0

[27] M. J. Afzal, F. Javaid, S. Tayyaba, M. W. Ashraf, and M. K. Hossain, (2020), "Study on the Induced Voltage in Piezoelectric Smart Material (PZT) Using ANSYS Electric \& Fuzzy Logic," in Proceedings of International Exchange and Innovation Conference on Engineering \& Sciences (IEICES), pp. 313-318. https://doi.org/10.5109/4102508

[28] F. Chen, Z. Liu, Z. Guan, Z. Liu, X. Li, Z. Deng, (2018), "Chloride-passivated Mg-doped $\mathrm{ZnO}$ nanoparticles for improving performance of cadmium-free, quan-tum-dot lightemitting diodes," ACS Photonics, Vol. 5, pp. 3704-3711. https://doi.org/10.1021/ acsphotonics.8b00722

[29] V. Khorramshahi, J. Karamdel, and R. Yousefi, (2019), "High acetic acid sensing performance of Mg-doped $\mathrm{ZnO} / \mathrm{rGO}$ nanocomposites," Ceramics Interna-tional, Vol. 45, pp. 7034-7043. https://doi.org/10.1016/j.ceramint.2018.12.205

[30] B. Uppalapati, A. Kota, V. P. Chodavarapu, and G. Koley, "An AlGaN/GaN Based UV Photodetector Simulation Using COMSOL to Obtain the Fresnel Coeffi-cients."

[31] N. Tariq, S. Tayyaba, M. W. Ashraf, G. Sarwar, and M. F. Wasim, (2016), "Comparative simulation of silicon, PDMS, PGA and PMMA actuator for piezoe-lectric micropump," in 
2nd International Conference on Robotics and Artificial In-telligence (ICRAI), pp. 130135. https://doi.org/10.1109/icrai.2016.7791241

[32] H. A. Raza, M. Asad, S. Sultan, N. Shehzad, and M. Ali, (2017), "Effect of heliostats reflectivity on the cost of solar thermal tower power plant," in Interna-tional Conference on Energy Conservation and Efficiency (ICECE), pp. 11-15. https://doi.org/10.1109/ece.2017. $\underline{8248821}$

[33] M. Sriubas, K. Bockute, D. Virbukas, and G. Laukaitis, (2015), "Dynamics of electrical charge carriers in Mg-doped TiO2 thin films under reducing conditions," Journal of Vibroengineering, Vol. 17, pp. 3333-3340. https://doi.org/10.1016/j.proeng.2014.12.500

[34] S. K. Dhandapani, (2020), "Perovskite Based Catalysts for Dry Reforming of Methane," State University of New York at Buffalo.

[35] G. S. Butt and M. W. Ashraf, (2020), "Parametric estimation of Group II el-ement doped zinc oxide nanostructures using fuzzy logic," Journal of Intelligent \& Fuzzy Systems, pp. 1-11. https://doi.org/10.3233/jifs-179674

[36] B. Ali, M. W. Ashraf, and S. Tayyaba, (2019), "Simulation, Fuzzy Analysis and Development of ZnO Nanostructure-based Piezoelectric MEMS Energy Har-vester," Energies, Vol. 12, pp. 807. https://doi.org/10.3390/en12050807

[37] P. Sahoo, A. Sharma, and R. Thangavel, (2019), "Hydrothermal synthesis, structural and optical investigations of undoped and $\mathrm{Mg}$ doped $\mathrm{ZnO}$ nanorods," in AIP Conference Proceedings, pp. 020095. https://doi.org/10.1063/1.5098649

\section{Authors}

Saher Manzoor is a Ph.D. scholar in Department of Physics, Government College University, Lahore, Paskistan, and a Visting Lecturer, University of Education, Lahore, Paskistan.

Maham Akhlaq is a Research Assistant and Visiting Lecturer, Department of Physics (Electronics), Government College University, Lahore, Paskistan. maham 9458@hotmail.com

Nimra Tariq Butt is a Ph.D. Scholar, Department of Physics, Government College University, Lahore, Paskistan. minnayjabeen@gmail.com

Muhammad Faisal Wasim is Assistant Professor, Department of Physics, Government Dyal Singh College, Lahore, Paskistan. rfwasim@yahoo.com

Article submitted 2021-02-09. Resubmitted 2021-03-22. Final acceptance 2021-03-23. Final version published as submitted by the authors. 